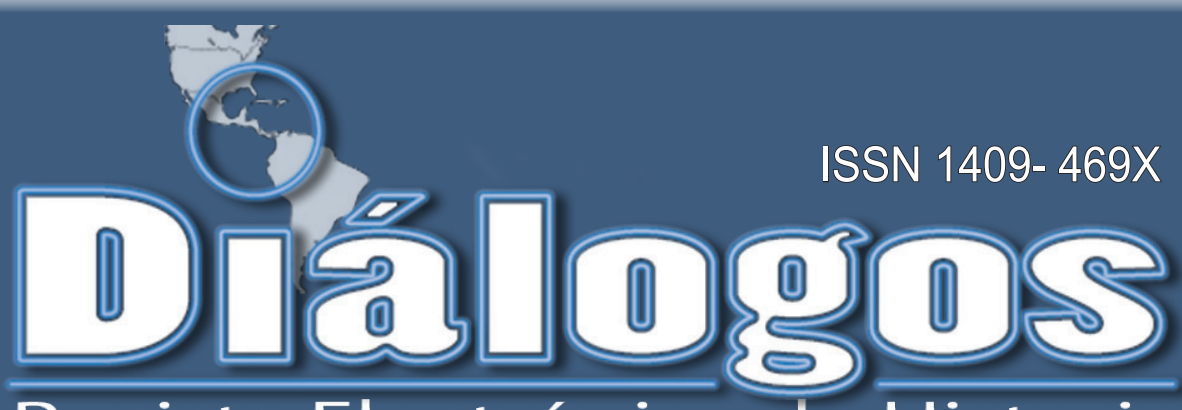

Revista Electrónica de Historia

Escuela de Historia. Universidad de Costa Rica Vol. 12 No. 2 Setiembre 2011 - Febrero 2012

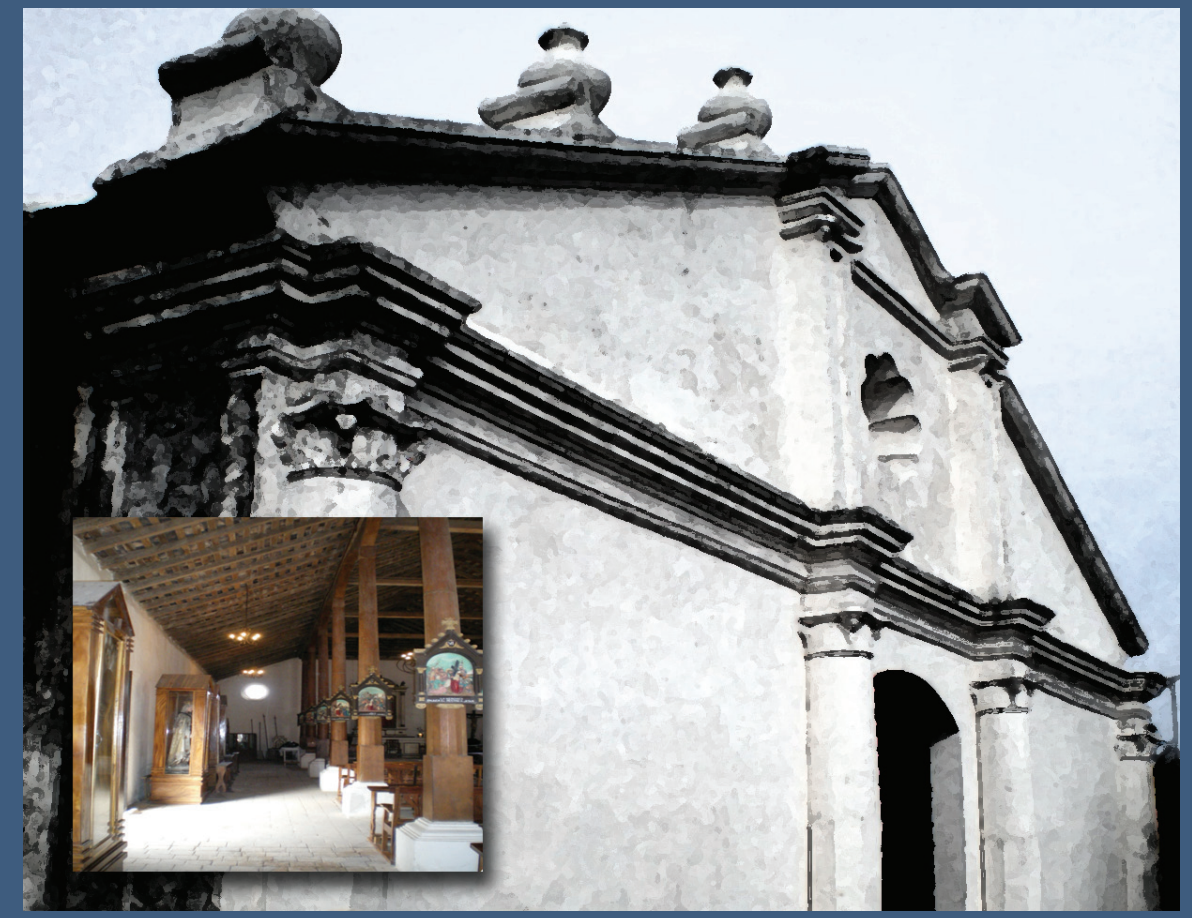

\title{
LA EVALUACIÓN DE LA PERCEPCIÓN ESPACIAL Y EL PESO CARTOGRÁFICO DE LOS NÓDULOS DEL ÍNDICO Y PACÍFICO, SIGLOS XVI-XVIII.
}

\section{Dr. Antoni Picazo Muntaner}

Director de la Revista: Dr. Juan José Marín Hernández juan.marinhernandez@ucr.ac.cr

Editor académico: Dr. Ronny Viales Hurtado - ronny.viales@ucr.ac.cr Editor técnico: M.Sc. Marcela Quirós G. - marcela.quiros@ucr.ac.cr Asistente: Cindy Chaves U. http://historia.fcs.ucr.ac.cr/dialogos.htm 


\section{Miembros del Consejo Editorial:}

Dr. Ronny Viales Hurtado. Catedrático. Historia Económica y Social. Universidad de Costa Rica ronny. viales@ucr.ac.cr

Dr. Guillermo Carvajal. Geografía Humana. Universidad de Costa Rica.

MSc. Francisco Enríquez. Historia Social. Universidad de Costa Rica.

MSc. Bernal Rivas Especialista en Archivística.

Universidad de Costa Rica.

MSc. Ana María Botey. Historia de los movimientos sociales. Universidad de Costa Rica.abotey@gmail.com

\section{Miembros del Consejo Asesor Internacional:}

Dr. José Cal Montoya. Universidad de San Carlos de Guatemala. jecalm@correo.url.edu.gt

Dr. Juan Manuel Palacio. Universidad Nacional de San Martín.jpalacio@unsam.edu.ar

Dr. Eduardo Rey. Universidad de Santiago de Compostela.ereyt@usc.es

Dr. Heriberto Cairo Carou. Departamento de Ciencia Política y de la Administración III - Universidad Complutense de Madrid. hcairoca@cps.ucm.es

Dra. Rosa de la Fuente. Departamento de Ciencia Política y de la Administración III Universidad Complutense de Madrid rdelafuente@cps.ucm.es

Dr. Javier Franzé. Departamento de Ciencia Política y de la Administración III Universidad Complutense de Madrid. javier.franze@cps.ucm.es

Dr. Jaime Preciado Coronado japreco@hotmail.com

Dr. Gerónimo de Sierra. Vicerrector de la Universidade Federal da Integração Latino-Americana (UNILA) y Departamento de Sociología, Facultad de Ciencias Sociales de la Universidad de la República. geronimo@fcs.edu.uy

Dr. Antonio Palazuelos. Departamento de Ciencia Política y de la Administración III - Universidad Complutense de Madrid.palazuelosa@cps.ucm.es

Dr. Werner Mackenbach. Universidad Potsdam. werner.mackenbach@uni-potsdam.de

Dr. Guillermo Castro. Ciudad del Saber Panamá. gcastro@cdspanama.org

Dra. Natalia Milanesio. University of Houston. nmilane2@Central.UH.EDU
Dr. Ricardo González Leandri. Consejo Superior de Investigaciones Científicas - España. rgleandri@gmail.com

Dra. Mayra Espina. Centro de Estudios Psicológicos y Sociológicos, La Habana. mjdcips@ceniai.inf.cu

Dra. Montserrat Llonch. Departamento de Economía e Historia Económica Universidad Autónoma de Barcelona montserrat.llonch@uab.es

Dra. Estela Grassi. Universidad de Buenos Aires. estelagrassi@gmail.com

Portada:

Fotografía: Volumen 12- No. 2, artículo 5 "Historia de la Ermita de Nuestro Señor de la Agonía. Liberia Guanacaste" de Edgar Solano.

"Diálogos Revista Electrónica de Historia" se publica desde octubre de 1999.

\section{Diálogos está en los siguientes repositorios:}

Dialnet

http://dialnet.unirioja.es/servlet/revista?tipo_busqueda=CODIGO\&clave_revista=3325

Latindex

http://www.latindex.unam.mx/larga.php?opcion=1\&folio=12995;

REDALYC

http://redalyc.uaemex.mx/src/inicio/FrmBusRevs2.jsp?iEdoRev=2\&cvepai=11;

LANIC

http://lanic.utexas.edu/la/ca/cr/indexesp.html;

Repositorio de Revistas Universidad de Costa Rica http://www.latindex.ucr.ac.cr/

Directorio y recolector de recursos digitales del Ministerio de Cultura de España

http://roai.mcu.es/es/inicio/inicio.cmd

DOJAC Directory of open access \& Hybrid journals http://www.doaj.org/doaj?func=byTitle\&hybrid=1\&query=D

Biblioteca de Georgetown

http://library.georgetown.edu/newjour/d/msg02735.html

Asociación para el Fomento de los Estudios Históricos en Centroamérica

http://afehc.apinc.org/index.php?action=fi_aff\&id=1774

Universidad de Saskatchewan, Canadá

https://library.usask.ca/ejournals/view/1000000000397982

Monografias

http://www.monografias.com/Links/Historia/more12.shtml

Hispanianova

http://hispanianova.rediris.es/general/enlaces/hn0708.htm 
Universidad del Norte, Colombia

http://www.uninorte.edu.co/publicaciones/memorias/enlaces.html

Universidad Autónoma de Barcelona

http://seneca.uab.es/historia/hn0708.htm

Repositorio Invenia - Gestión del Conocimiento

http://www.invenia.es/oai:dialnet.unirioja.es:ART0000086144

Enlace Académico

http://www.enlaceacademico.org/biblioteca/revistas-en-formato-digital-centroamerica/

\section{Electronic Resources}

http://sunzi1.lib.hku.hk/ER/detail/hkul/3987318

Revistas académicas en texto completo

http://web.prw.net/ vtorres/

Diálogos se anuncia en las siguientes

instituciones y sitios académicos:

Maestroteca

http://www.maestroteca.com/detail/553/dialogos-revista-electronica-de-historia.html

Biblioteca de Georgetown

http:/library.georgetown.edu/newjour/d/msg02735.htm

Asociación para el Fomento de los Estudios Históricos en Centroamérica

http://afehc.apinc.org/index.php?action=fi_aff\&id=1774
Universidad de Saskatchewan, Canadá

https://library.usask.ca/ejournals/view/1000000000397982

\section{Monografias}

http://www.monografias.com/Links/Historia/more12.shtml

\section{Hispanianova}

http://hispanianova.rediris.es/general/enlaces/hn0708.htm

Universidad del Norte, Colombia

http://www.uninorte.edu.co/publicaciones/memorias/enlaces.html

Universidad Autónoma de Barcelona

http://seneca.uab.es/historia/hn0708.htm

Repositorio Invenia - Gestión del Conocimiento

http://www.invenia.es/oai:dialnet.unirioja.es:ART0000086144

\section{Enlace Académico}

http://www.enlaceacademico.org/biblioteca/revistas-en-formato-digital-centroamerica/

\section{Electronic Resources}

http://sunzi1.lib.hku.hk/ER/detail/hkul/3987318

Revistas académicas en texto completo

http://web.prw.net/ vtorres/

La revista electrónica Diálogos es financiada por la Vicerrectoría de Investigación de la Universidad de Costa Rica

\section{Citado en Dialnet - Latindex-}

Redilac- Directorio y recolector de recursos digitales del

Ministerio de Cultura de España cc creative 


\title{
Palabras claves
}

Percepción, espacio, comercio, Índico, Pacífico.

\section{Keywords}

Perception, space, trade, Indian Ocena, Pacific Ocean.

Fecha de recepción: 3 mayo 2011 - Fecha de aceptación: 1 de octubre 2011

\begin{abstract}
Resumen
El trabajo que presentamos es una análisis pormenorizado de la evolución espacial que el hombre europeo desarrolló de los grandes nódulos comerciales del sudeste asiático. Partiendo de un análisis teórico, y analizando 250 mapas, hemos secuenciado el proceso de percepción geográfica y mercantil entre 1500 y 1800 . Por ello hemos realizado dos cómputos: el peso cartográfico absoluto de los grandes puertos y, en segundo lugar, el peso cartográfico relativo. Ello nos permite saber que era lo que se "percibía" y determinar el "ritmo" de la evolución de la percepción espacial.
\end{abstract}

\begin{abstract}
The work we are presenting is a detailed analysis of developments in space as men of the great European developed nodules trade in Southeast Asia. Based on a theoretical analysis, and analyzing 250 maps, we have sequenced the process of perception and geographic market between 1500 and 1800. We have conducted two computations: mapping the weight of all the major ports, and secondly, the relative weight mapping. This lets us know that was what was "perceived" and determine the "pace" of changing the perception of space.
\end{abstract}

Dr. Antoni Picazo Muntaner: Universitat de les Illes Balears. Departamento de Ciencias Históricas y Teoría de las Artes. Email.: apicazo@uib.es. tef. 654122080 cortespicazo@terra.es Dr. Antoni Picazo, licenciado y doctor en Historia por la Universitat de les Illes Balears, también es licenciado en Geografía. Ha publicado libros como «El espacio imaginario. La geografía fantástica como fenómeno de colonización en América del Norte », « La cultura de la Ilustración en Mallorca », «Los chuetas de Mallorca, criptojuadismo y grupos de poder », «Urbanismo y clases sociales en Mallorca, 1576-1818 »,...También ha participado en diferentes revistas especializadas y congresos tanto nacionales como internacionales. 


\title{
LA EVALUACIÓN DE LA PERCEPCIÓN ESPACIAL Y EL PESO CARTOGRÁFICO DE LOS NÓDULOS DEL ÍNDICO Y PACÍFICO, SIGLOS $\mathrm{XVI-XVIII*}$
}

\author{
Dr. Antoni Picazo Muntaner
}

\section{INTRODUCCIÓN.}

Analizar las raíces y los factores que surgieron de la primera Edad Global ${ }^{1}$ significa, en definitiva, profundizar en el estudio del desarrollo del capitalismo, aunque en una dimensión mucho más amplia. No es nuestra intención entrar en las discusiones sobre la definición del capitalismo y los orígenes de su nacimiento -ya hubo debates muy intensos en su tiempo-; aunque sí lo es introducir nuevos conceptos que faculten un mayor entendimiento y compresión de los problemas que afectaron a la sociedad de esa época. También lo es verificar hasta que punto las distintas dinámicas de colaboración y cooperación (entre ellas la cartografía) permitieron y formaron parte de aquel salto tan espectacular.

El estudio que realizamos se incluye en un proyecto mucho más amplio, se trata de "Dynamic Complexity of Cooperation-Based Self-Organizing Networks in the First Global Age" (DynCoopNet), del cual forman parte historiadores, matemáticos, sociólogos, geógrafos, cartógrafos, economistas,... como se ve un conjunto muy amplio de especialistas con una finalidad común: desarrollar una nueva concepción interdisciplinar para abordar la cooperación en redes no lineales durante esa primera Edad Global, introduciéndose mecanismos de análisis con Sistemas de Información Geográfica espacio-temporales y otros de visualización de redes.

La investigación que aquí presentamos se centra en un área muy concreta: el subsistema Indopacífico. Creemos que con esa primera globalización de mercados se desarrolló un sistema único que al final se impondría en todo el orbe: el capitalismo. Ese sistema no deja de ser una red y, por tanto, como gran unidad, como totalidad, tenía otros subsistemas interconectados que lo estructuraban como un todo. Por una parte el subsistema Atlántico-mediterráneo; por otra el Indo-pacífico. La fusión de ambos configuró esa nueva dinámica contractual y mercantil del momento que permitió diseñar un nuevo esquema de pensamiento, de actividad y, sobre todo, de organización. Efectivamente, iniciamos nuestra investigación, sobre un primer vector de penetración: la visión espacial del hombre europeo. Hemos abierto una línea de aproximación teórico-experimental a ese esquema de pensamiento siguiendo las pautas metodológicas de Braudel $^{2}$. En un segundo orden de importancia, y basándonos en los postulados teóricos de algunos autores que han 
trabajado la percepción y la imagen, hemos analizado detenidamente cuales fueron los nódulos más importantes que se reflejaron en la cartografía del momento. Ciertamente, hemos estudiado 250 mapas que abarcan el período de 1400 a 1800; mapas de diferente tipología, y de autores de procedencias geográficas dispares. Ello nos ha procurado un primer modelo perceptivo. Estos primeros resultados los hemos comparado con los puertos de destino, principales y secundarios, de las naves de la VOC y de la EIC. Las revelaciones, aún sabiendo que partíamos de un modelo teórico experimental, han sido más que positivas pues han avalado nuestro análisis cartográfico.

\section{METODOLOGÍA.}

A fines de la Edad Media el hombre europeo ya tenía pleno conocimiento de los principales nódulos y redes de comercio de los mercados lejanos, especialmente de los situados en el área Indoasiática. Ese conocimiento implicaba, necesariamente, una imagen geoespacial propia, definida y, sobre todo, vinculada a un deseo emergente. Deseo que con el tiempo se desarrollaría, se perfeccionaría y finalmente sería alcanzado: la necesidad de acceder a ellos, reduciendo costes y ampliando los beneficios que derivaban del comercio. Percepción ésta que se extendería y se ampliaría con el desarrollo de la cartografía ${ }^{3}$ en un proceso de retroalimentación constante pues "percibir es ver". Sobre este tema algunos autores clásicos no estuvieron del todo de acuerdo, como Berkeley ${ }^{4}$ que pensaba que lo fundamental en la percepción no era la "visión", sino el contacto "táctil". No obstante, podríamos sintetizar ese proceso con una definición más simple: “...El orden espacial es un concepto abstracto. La percepción concreta se refiere a figuras, direcciones, posiciones, magnitudes y distancias. La finalidad de estos conceptos es introducir orden en la inmensidad..." ${ }^{5}$. En cierta forma esta definición encierra una ecuación de poder muy lógica: ver es información, y ésta se transmuta en conocimiento, lo que puede llevar -y de hecho llevó- a relaciones de poder y de control. Sobre este punto E. W. Fox escribió “...El comercio depende de instrucciones y registros escritos...implica viajes, lo que invita a la atención, la discusión y la comparación...”6. Esa misma visión del espacio sería la que desarrollarían las incipientes monarquías nacionales de Europa mediante la elaboración de una política expansiva que los llevaría más allá de las fronteras del viejo continente.

Por ello, y a medida que la percepción de los primeros grandes Estados nacionales iba perfeccionándose, desde el poder ${ }^{7}$ se empezaron a gestar nuevas ideas de control que provocarían grandes cambios en la propia estructura económica, social y política de Europa. Así pues, durante la primera Edad Global, cuando el comercio adquirió por primera vez una amplitud desconocida hasta la época ${ }^{8}$, el mapa se 
convirtió en inteligencia, “...una representación del conocimiento, la representación se construye de acuerdo con elementos culturalmente definidos, los códigos semióticos; el conocimiento se construye con diversidad de elementos intelectuales así como tecnologías instrumentales. Pero también el conocimiento y sus representaciones son construidos por individuos que trabajan para y dentro de diversas instituciones..."9. La representación del espacio no afectaba sólo a los mercaderes y a las diferentes compañías que intervenían en el trato y contrato de géneros, también interesó a los Estados que estaban diseñando sus propias políticas expansivas. Eran los mismos momentos en que se penetraba en la configuración global de los mercados.

Mucho se ha escrito sobre el espacio y la percepción, no es nuestra intención desarrollar una teoría psicológica de cómo se percibe, sino sus implicaciones en la actividad comercial, el concreto análisis de la evolución. En 1947 R. MacLeod propuso la tesis de "geografía psicológica" en la misma línea J.K. Wright establecía la "geosofía", cómo se formaba la idea de percepción espacial. Para M. Sprout la percepción consistía en el desarrollo de "imágenes e ideas"; para Morley, en cambio, las imágenes sólo pueden ser estudiadas desde la percepción personal del individuo. De esas teorías nacieron las actuales líneas de investigación en la percepción espacial: análisis de la estructura (la naturaleza de la percepción del mundo); el análisis de la evaluación (los hechos entre la percepción del mundo y las decisiones) y el análisis de la preferencia, cómo se evalúan unos objetos frente a otros ${ }^{10}$. Nuestro propósito, por tanto, es el de determinar cómo afectó la percepción del mundo ${ }^{11}$ a la toma de decisiones, tanto de compañías mercantiles como de las grandes monarquías del inicio de la Edad Moderna. La investigación en el proceso de la lectura del mapa es relativamente escasa. Sin embargo, hay dos grandes temas que se hallan en franca emergencia. Desde la psicología se investiga en el desarrollo de la lectura y representación espacial; Siegel y White estudian la conexión de rutas; Appleyard, por su parte, profundizó en el modo de conexión de nódulos y rutas. El desarrollo cartográfico, y una mejor percepción del entorno geográfico pero sobre todo de los mercados lejanos, facilitarían que Europa inmersa en el proceso de transición del feudalismo al capitalismo generase nuevas fuerzas, tanto mentales como conceptuales, que facilitarían, aún más, su pleno desarrollo ${ }^{12}$. No sería un proceso simple, ni tan siquiera corto, pero sí fructífero en todas sus vertientes. La interrelación, cada vez más profunda, entre cartografía, comercio, redes y poder llevaría al conocimiento geográfico y al incremento del tráfico mercantil. Esa situación, perfeccionada por las grandes compañías europeas del siglo XVII, acabaría por facilitar el dominio tanto de los nódulos como de esas mismas redes.

Partimos del convencimiento que es necesario analizar todas las imbricaciones entre espacio ${ }^{13}$ y comercio -e incluso entre espacio y poder- y penetrar en la dinámica de la percepción geográfica y económica. Es evidente que las obras de los cartógrafos ayudaron a perfeccionar, y aún a configurar, una Imago mundi 
destinada a un "lector". Por eso necesitaron canales de información que pudieran fomentar esa relación de conectividad entre ambos protagonistas. Se iniciaba una nueva configuración mental del hombre europeo ${ }^{14}$ que al final posibilitaría un cambio asombroso en la visualización espacial y en las relaciones de dominiodependencia. Para analizar la evolución espacial que se gestó en Europa del área Indopacífica en la primera Edad Global hemos procedido a analizar 250 mapas de la época, que abarcan una sección temporal que va desde 1400 hasta 1800 . Este análisis lo hemos realizado siguiendo una serie de pautas.

Hemos partido del análisis de los mapas (recordemos que la colaboración para su elaboración era fundamental, pues los cartógrafos se basaron en las informaciones recibidas de pilotos, marineros, mercaderes...) de la misma región abarcando el período de 1400 a 1800 . Esta elección nos ha permitido definir dos cuestiones esenciales que nos permitirán profundizar en las relaciones y las colaboraciones entre las redes comerciales portuarias de la zona. A partir de esa cartografía hemos estudiado la evolución de la representación temporal de los puertos de la zona, el peso de la imagen cartográfica que tenía cada uno de ellos. La secuenciación de puertos ${ }^{15}$ nos ha facultado, a la par que trabajar las conectividades de la red mercantil ${ }^{16}$, poder determinar el peso absoluto que tenían cada uno de ellos. Recordemos que los mapas son elaborados con criterios subjetivos, no es la realidad misma, sino una mera representación. Los cartógrafos "seleccionan", establecen unos criterios para su perfil que son claramente personales. Esta "subjetividad" es muy valiosa para determinar que "impacto" tenía cada uno de los puertos en la sociedad en que el autor desarrolló su mapa ${ }^{17}$. Los mapas analizados los hemos estudiado por períodos de 25 años para establecer la secuencia de aparición en las obras de los principales puertos. En este aspecto, el mecanismo de elaboración es simple. En primer lugar y como ya hemos citado, hubo un trasvase de información entre una parte (exploradores, marineros, capitanes, mercaderes...) que realizó viajes sobre el terreno; y otra, que "acumuló información". Pero este trasvase aunque se gestó sobre principios pragmáticos y empíricos incidió en el propio cartógrafo, recreando en él un "imaginario" propio, algunas veces retro alimentado sobre una realidad muy concreta, otras activó elementos quiméricos que siguieron apareciendo en la cartografía hasta principios del siglo XIX. En cierta forma, la información posibilitó realzó los resortes más imaginativos del cartógrafo.

Para ello hemos utilizado la mayor variedad posible: desde cartas náuticas y roteiros, hasta mapas mundi o atlas; en cuanto a su zona de producción también la hemos diversificado al máximo, empleando portugueses, españoles, franceses, ingleses, italianos, holandeses, alemanes,... Esta diversidad, tanto de los cartógrafos como de tipología cartográfica, nos ha permitido desarrollar una mayor visión de conjunto ${ }^{18}$.

Siguiendo con el aspecto de la fragmentación temporal éste responde a un criterio lógico. En veinticinco años se puede transferir la información de mercaderes 
y marineros a los cartógrafos para mutar la percepción espacial o la configuración de nuevos puertos. La posible segmentación temporal en series menores habría hipotecado la evolución de la cartografía al no presentar ninguna variación, mientras que la secuencia temporal a más largo plazo habría desfigurado por completo esa misma percepción al visualizarse cambios espectaculares, sin posibilidad de ubicar temporalmente su inclusión en la percepción europea. A partir de este análisis hemos pasado a valorar y a definir, pues partimos de un aspecto muy teórico y experimental, los "pesos cartográficos", tanto los relativos como los absolutos. Definimos como "peso relativo", partiendo de los estudios de redes topológicas, el número de veces que un mismo puerto aparece en un examen cartográfico de quince mapas diferentes durante un cuarto de siglo. Por ello mismo el peso absoluto es la suma de los diferentes pesos relativos tanto en una centuria concreta como de la suma de los pesos relativos de todo el periodo cronológico que hemos abarcado (1400-1800).

\section{NUEVOS MUNDOS, NUEVOS MERCADOS, NUEVAS IMÁGENES.}

Desde que los portugueses abrieron la ruta del Cabo de Buena Esperanza ${ }^{19}$ el negocio de las especias del sudeste asiático tuvo grandes y cualitativos cambios. El primero de ellos, sin duda, fue el completo dominio de los mercaderes lusos y el ocaso, en la misma región, de las viejas redes comerciales musulmanas ${ }^{20}$. Sin embargo, en el siglo XVI, la época en que se fraguó el comercio global, ese monopolio no podía durar demasiado. Las voces, cuando no los viajes, para truncarlo aparecieron tempranamente.

La primera discusión vino de los españoles y lo fue para limitar la zona de influencia portuguesa que se habían repartido en Tordesillas. El viaje de Magallanes al "mundo todo", abrió las puertas a un primer debate. Un debate surgido de la "omisión" de algunos puntos vitales en el Tratado de Tordesillas. Sin embargo, las conversaciones que se efectuaron en Badajoz y Elvas entre castellanos y portugueses quedaron paralizadas, no por la indefinición del mundo de los cartógrafos y pilotos que allí estuvieron presentes, sino por las propias directrices que las diferentes coronas ${ }^{21}$ estaban dictaminando. Pronto la situación, como era de esperar, tuvo un rápido cambio. El joven monarca, Carlos, necesitaba capital líquido para sus pretensiones europeas. De ahí que "cediera" las islas del Maluco a los portugueses. El problema del monopolio parecía salvado. El respiro, previo pago, de los portugueses fue muy notable. La zona en discusión podría afectar las tres grandes plataformas comerciales del sudeste asiático: Malaca -desde la cual se alcanzaba los mercados de Sumatra y Sunda -, Java -que abarcaba la gran área de Bali, Timor y el Maluco- y, finalmente, el gran mercado chino, extraordinariamente valioso por cuanto la relación bimetálica oro-plata se situaba en 12:9 en 1500 y 12:6 en 1575 . 
Efectivamente, la secuencia temporal de 1500 a 1525 fue, sin duda, de auge para Portugal, de explotación y reconocimiento de los nuevos mares, de los nuevos puertos, de las nuevas rutas. En 1516 Fernao Peres de Andrades salió de Goa con la intención de alcanzar los grandes puertos de China, pasando por Sumatra y Cochinchina. No obstante el mal tiempo le hizo retroceder, no sin antes visitar Siam y Malaca. $\mathrm{Al}$ año siguiente su fortuna fue mayor y alcanzó, definitivamente, el puerto de Cantón. En esas dos primeras décadas los portugueses estaban dispuestos para controlar y monopolizar el destino, y con ello los precios, de los productos asiáticos más demandados en Europa, entre ellos las especias. Esa información, ya profundizaremos en ella más adelante, fue traspasada a la cartografía y a las cartas náuticas $^{22}$, los instrumentos básicos para acceder a los mercados lejanos. Esos mercados lejanos que, tiempo atrás, habían explotado los persas, los árabes, indios y $\operatorname{chinos}^{23}$. Europa continuaba demandando los productos de esa lejana región del orbe. Pero algo había cambiado. Los europeos aprendieron que sería fácil, y barato, suplantar a todos los intermediarios del sistema mercantil de productos asiáticos y establecer su control sobre los mismos. El acceso directo a esos mercados lejanos de Asia no era fácil, y más si se tiene en cuenta que la navegación de la época, aunque en pleno y continuo desarrollo, aún no estaba perfeccionada. La localización de un puerto, sin los instrumentos, pero sobre todo, sin la cartografía adecuada podía hacer fracasar cualquier empresa, por bueno que fuese el capitán. Esos problemas fueron superados rápidamente por los portugueses.

En primer lugar, porqué contrataron a pilotos de la zona: indios, musulmanes... lo cual facilitó la adquisición de "información", ello redujo los costes a mínimos pues cualquier empresa partía con una gran ventaja inicial. En segundo lugar, y ya en una fase ulterior, la constante producción cartográfica, cartas náuticas y roteiros, facilitaron a los pilotos europeos las herramientas necesarias para poder acceder a todos los puertos del Índico y del Pacífico con el menor riesgo posible. Esa información era absolutamente necesaria, muy importante para poder integrar la red de mercados en el seno de los intereses monopolísticos portugueses. Por tanto, se podían contabilizar como un componente más de las transacciones. Oliver Volckart ${ }^{24}$ recogió la propia definición que de "costes de información" realizó Yoram Brazel "the cost associated with the transfer, capture, and protetion of right". También, como no, el desarrollo del incipiente capitalismo necesitaba no solo del tráfico del Atlántico, sino también del sudeste asiático. G. Knaap y H. Sutherland ${ }^{25}$, afirmaron que el capitalismo requería un conocimiento profundo del comercio de larga distancia.

\section{LA CARTOGRAFÍA DE LOS MERCADOS LEJANOS.-}

En 1502 Cantino $^{26}$ elaboró un extraordinario planisferio en el que se incorporaban todos los nuevos descubrimientos, con importantes notas de referencia a 
Ceilán donde se comercializaban perlas, oro, plata y piedras preciosas. El mapa de Cantino exhibe solo un fragmento de la costa americana, aunque dibuja la línea de demarcación entre España y Portugal. En la zona del Pacífico reflejó mercados asiáticos como Singapore ${ }^{27}$ o puertos chinos. La proyección estereográfica de Giovanni Contarini ${ }^{28}$, de 1506, sigue las mismas pautas que el de Cantino, aunque en este caso la perspectiva sea polar. Contarini dibujó fielmente el perfil africano, la India, Ceilán, así como Java, Quinsay y Cipango, a los que ubicó junto a la isla de Cuba. Por lo que se refiere a la interpretación del Nuevo Mundo, su lugar, y su relación con Asia debemos hablar del mapa de Bartolomé Colón y de Alessandro Zorzi de 1503, que recogió los descubrimientos del Almirante -así como su interpretación de las tierras recién halladas-. Tanto Bartolomé Colón como Zorzi fundieron el Nuevo Mundo con Asia, ubicando la Española justo en el centro del Océano, a medio camino de Europa. En cuanto a la geografía asiática ubicaron Ceilán, Ormuz, Sumatra, y en Catai los puertos de Caramburu y Belporto El mapa de Fries de 1522 reflejó algunas de las ciudades comerciales de la India o Ceilán mientras que en China la única gran ciudad comercial aludida fue Quinsai. De la misma época, 1525 , pero sin duda mucho más completo, trabajado y perfecto es la carta Castiglioni que recogió todos los descubrimientos realizados por los europeos, tanto en el Índico como en el Mar del Sur. Entre las islas del Mar del Sur destacamos la de los Ladrones, Canela, Gilolo, Timor,... la costa asiática de China presenta detalles suficientes de un conocimiento perfecto, como los arrecifes de la Punta de la Vera Cruz, Cantón o puertos de Cochinchina y Camboya. En el Índico destacan los perfiles costeros de la India, con la ubicación de las grandes ciudades comerciales: Goa, Cambay, la isla de Ceilán, Sumatra, la correcta posición de las Maldivas, en los que incluyó algunos bajos de arrecifes de la zona.

El atlas de Lopo Homen ${ }^{29}$ de 1519 presenta un indefinido golfo entre China y América, con innumerables islas y un Cipango clásico, de forma casi rectangular; una curiosidad -comercial- de este mapa son la multitud de naves musulmanas surcando el Mar de China junto a naves portuguesas, competidoras por los productos de Cantón, reflejo de la realidad en que estaba inmerso el autor. De esa misma época tenemos el mapa de Francisco Rodríguez, de 1513, con unas definiciones costeras de Java y Sumatra muy bien logradas así como la ubicación del golfo de Tonquín y de Cantón, aunque la costa norte de China es muy irregular. El planisferio de Diego Ribeiro "Carta Universal en que se contiene todo lo que en el mundo se ha descubierto ", de 1527 refleja prácticamente todo el orbe conocido -a excepción de la costa oeste de América del Norte-. El mismo autor en el mapa de 1529 ya incluyó China y, concretamente, el gran puerto de Cantón. La velocidad de representación y asimilación cartográfica de los nuevos territorios fue, pues, a la par que rápida, sorprendente. Entre 1558 y 1568 sobresalen tres grandes atlas de Diogo Homen $^{30}$, el de 1558 es el más primitivo, con una representación del Japón muy 
indefinida pero con unas referencias a Filipinas bastante mejores. La información del mapa de 1560 fue bastante más numerosa, lo que le permitió incidir en la representación de varias islas. Todo ello fue perfeccionado en 1568, en que ya localizó los principales bajos a los que tenían que enfrentarse las naos portuguesas y una localización mucho más lograda de los principales puertos chinos. Definición que también aparece en los mapas de Bartolomeu Velho, 1560; Lázaro Luis, 1560; Sebastiao Lopes, 1565 -con referencias a Cantón, Japón, Mindanao y Maluco casi perfectas-; Bartolomé Lasso, 1590; Luis Teixeira, 1595, éste último con la costa de Japón, Corea y China en la posición casi correcta; o de Fernao Vaz, 1575. Un caso ejemplar de lo que venimos afirmando lo tenemos en los mapas de Luis Jorge de Barbuda, de 1575. En sus mapas Barbuda definió de una forma bien lograda tanto Filipinas como los principales puertos chinos y Japón. Sin embargo, es en el mapa de Inacio Monteiro de 1581 donde se ofrece una definición más alta del Japón así como una descripción interna más útil y provechosa, dividiéndolo en provincias.

Por lo que se refiere al Índico y al Pacífico, y concretamente a los extraordinarios mercados de China y Japón, hallamos tres grandes épocas en la confección cartográfica que permitiría a las naos surcar aquellos mares en demanda de todos los productos que tan altos beneficios daban.

En primer lugar hallamos una geografía inductiva ${ }^{31}$ (gestada generalmente en gabinete) con muchas descripciones y complementada con una percepción sagaz de un espacio aún desconocido. Las características principales de esta primera fase son, básicamente, las siguientes: un primer estadio donde se reflejó un espacio referencial de ubicación de los grandes mercados derivada principalmente de narraciones literarias, si bien con una indefinición muy alta de la línea costera, lo que algunos psicólogos de la Gestalt, como Erich Rudolf Jaenchs calificarían como "eidética", a saber una "imagen de la percepción espacial".

En una segunda fase, la percepción y ubicación cartográfica mejoró debido a un incremento en la información transmitida por pilotos y autoridades a los cartógrafos $^{32}$, con unas referencias reales mucho más perfectas. Ello posibilitó la formación de una geografía -como elemento de poder- altamente desarrollada.

La tercera fase fue la de la perfección cartográfica, mucho más detallista ${ }^{33}$, en cierta forma fue la transición a la otra gran época cartográfica del siglo XVII en la que privó el detalle y la acumulación de información.

\section{CARTOGRAFÍA Y RED PORTUARIA EN EL ÍNDICO Y PACÍFICO.-}

Ciertamente, un mapa únicamente sirve para aquello que fue elaborado. Pero lo que a nosotros nos interesa es la "visión europea" de los nódulos del sudeste asiático. Determinar cuales de ellos eran percibidos con mayor importancia. Así, hemos 
utilizado cartas náuticas, roteiros, mapas mundi o atlas; en cuanto a la zona de producción de los mapas también la hemos diversificado, empleando mapas portugueses, españoles, franceses, ingleses, italianos, holandeses, alemanes, ingleses... Esta diversidad geográfica, tanto de los cartógrafos como de la diversidad tipológica de los mapas, nos han permitido desarrollar una mayor visión de conjunto.

Un mapa es una simplificación, una generalización de la propia realidad y, por ello, manifiesta la realidad subjetiva del autor, su propia mentalidad y sus centros de interés más importantes. Las distintas experiencias vivenciales, así como el desarrollo de una percepción particular, influyen en la visión de los distintos cartógrafos, y en especial, la colaboración -información- que se establece entre los diferentes agentes que posibilitan la redacción de $\operatorname{los}_{\text {mapas }}{ }^{34}$ (autoridades, marineros, cartógrafos, mercaderes....). En cierta forma la percepción es un proceso psicológico de la interpretación del mundo, del propio conocimiento directo y, por tanto, del mundo interior de las personas. Toda persona establece, en el ámbito inconsciente, un marco general de interpretación de la realidad. Percibir un espacio en un mapa necesita, además, un aprendizaje. Esta subjetividad posibilita que el individuo genere su "propia realidad", conforme a sus condiciones culturales y económicas, Vilà lo explicó de la siguiente forma: “...se trata de un espacio egocéntrico, cerrado en función de la experiencia personal y vital del hombre, particularizada por los procesos biológicos, sociales y culturales..."35. Esta subjetividad y la colaboración en la transmisión de los datos permite el tratamiento de la información, que Joly define: "analizar, comparar, simplificar es hacer lo que se llama el tratamiento de la información" 36 . Por tanto, cualquier intervención, cualquier composición abstracta de la propia realidad comporta una elección, es decir, una construcción subjetiva de la misma realidad que se realiza sobre unos deseos, sobre una meta concreta. Por ello, los mapas deben presentar una serie de factores para que tengan unas buenas cualidades: la precisión de la información que proporcionan; la correcta expresión, para valorar adecuadamente las informaciones; la legibilidad de la información proporcionada y la eficacia para alcanzar los objetivos propuestos.

Algunos postulados teóricos, filosóficos y psicológicos estudian y penetran en esa visión de la realidad. Para Bined ${ }^{37}$ “...el razonamiento de la percepción externa pertenece a la clase de razonamientos inconscientes...el razonamiento es una organización de imágenes, determinado solo por las propias imágenes...”. Según ello, para poder aprehender los nuevos descubrimientos cabría "visualizarlos" en forma de mapa. Lukács ${ }^{38}$ ya explicó: “...La simbología transforma la apariencia en idea, y la idea en imagen, de tal modo que la idea es en la imagen siempre infinitamente activa e inalcanzable..." o lo que es lo mismo, según Leland Swenson ${ }^{39}$, siguiendo las tesis de la Gestald, “....El aprendizaje se convierte en una cuestión de ver....o de ver la información como figura...” o la misma afirmación de Fitche ${ }^{40}$ “...ninguna representación es posible sin una imagen...”. En cambio Dancy ${ }^{41}$ explica que todo 
el "conocimiento" parte de nuestros estados sensoriales. Cassier ${ }^{42}$, por su parte, escribe: "A partir del instante en que el problema del espacio es visto y tratado con verdadera agudeza sistemática, va ocupando cada vez más claramente el concepto básico de lugar central". Para Luis Cencilio ${ }^{43}$ "El mundo, pues, no puede ser conceptuado en ningún caso como -cosa- y ni siquiera como conjunto de -cosas....sino como el campo de toda experiencia posible...en donde los acontecimientos se constituyen como realidades para el hombre...".

Tal vez un ejemplo de estas afirmaciones lo hallamos en el proceso de creación de Abraham Ortelio de su "Teatro de la Tierra Universal", de 1598. En este mapa Ortelio, informado de los productos más caros que llegaban a Europa, y de su lugar de procedencia, no dudó en reflejarlos en la introducción de su obra. Así, mercancías como el oro, eran acarreadas en Sumatra, Java o Mozambique; los diamantes en Palicate; las piedras preciosas en Ormuz; el márfil en Calicut, Cambai y Sumatra; el clavo en Molucas...etc.

A partir de 1500 los portugueses establecieron en el Índico toda una red de puertos para acceder a los mercados tanto de la misma zona como a la del Pacífico. En este aspecto, Kenneth McPherson afirmó que el Índico era “....una unidad esencial..." 44 determinada, en cierta forma, por el ritmo del comercio marítimo de larga distancia. En la mayoría de los casos esas plataformas contractuales creadas por los portugueses se constituyeron meramente como lugares clave para la actividad mercantil, sin ninguna otra actividad comercial de amplio desarrollo.

Así pues, los puertos del Índico en el siglo XVI reflejados en la cartografía, con su peso cartográfico relativo y absoluto, es decir, el valor de su representatividad para Europa (ver Cuadro 1).

La tabla nos permite visualizar las etapas perceptivas de los diferentes puertos, con una preponderancia absoluta para todas las épocas del puerto de Ormuz. Sin embargo, analizados por etapas cronológicas se llega rápidamente a la conclusión que toda el área del Golfo Pérsico y del Mar Rojo eran las más conocidas, las asimiladas más rápidamente debido al conocimiento previo de la Edad Media. En la segunda etapa cobran auge los puertos de la India que siguen con esta dinámica todas las etapas posteriores, integrándose Ceilán a partir de la segunda mitad de la centuria, y paulatinamente van cobrando importancia Pegú y Malaca. Para los puertos del Pacífico, la representación cartográfica se detalla en el Cuadro 2.

El examen nos demuestra claramente la importancia para toda la centuria del puerto de Cantón -y de toda el área china-, al que siguen en importancia Borneo y Aceh, estos dos últimos especialmente activos a partir de 1576. Como ya hemos mencionado anteriormente, a partir de la segunda mitad del siglo XVI el sistema monopolístico portugués en el sureste asiático comienza a romperse y a fragmentarse. Sin embargo, la época de disolución completa de ese mismo modelo arrancó en 1595, en los años previos a la formación tanto de la VOC como de la EIC. En 
Cuadro 1

\begin{tabular}{|c|c|c|c|c|c|}
\hline \multicolumn{6}{|c|}{ PUERTOS DEL ÍNDICO, SIGLO XVI } \\
\hline PUERTO & $1500-1525$ & $1526-1550$ & $1551-1575$ & $1576-1600$ & Peso Absoluto \\
\hline Mozambique & 4 & 2 & 4 & 4 & 14 \\
\hline Mombasa & 1 & 4 & 4 & 1 & 10 \\
\hline Quiloa & & 1 & 3 & & 4 \\
\hline Mogadiscio & & 1 & 3 & & 4 \\
\hline Sofala & 1 & 1 & 2 & 1 & 5 \\
\hline Melinde & 1 & 1 & 1 & 1 & 4 \\
\hline Merca & 1 & 1 & 2 & 1 & 5 \\
\hline Dar-Es-Salam & 1 & 1 & 2 & 1 & 5 \\
\hline Zalala & & 1 & 1 & & 2 \\
\hline Manakara & & 1 & 1 & 1 & 3 \\
\hline Ormuz & 9 & 5 & 9 & 9 & 32 \\
\hline Aden & 7 & 5 & 9 & 8 & 29 \\
\hline Masqat & 2 & 1 & 3 & 2 & 8 \\
\hline Chor Ruri & & & 1 & & 1 \\
\hline Sohar & & 1 & 6 & 1 & 8 \\
\hline Mocca & & & 2 & 1 & 3 \\
\hline Dofar & & 2 & 3 & 1 & 6 \\
\hline Quriat & & 2 & 2 & 1 & 5 \\
\hline Matrah & & & 1 & 1 & 2 \\
\hline Damao & 3 & 4 & 8 & 8 & 23 \\
\hline Calicut & 7 & 7 & 12 & 7 & 33 \\
\hline Kannur & 3 & 4 & 5 & 5 & 17 \\
\hline Diu & & 4 & 7 & 3 & 14 \\
\hline Goa & 3 & 4 & 11 & 7 & 25 \\
\hline Karwar & & & 2 & 1 & 3 \\
\hline Cambai & 3 & 3 & 8 & 4 & 18 \\
\hline Calcuta & & 1 & 3 & 1 & 5 \\
\hline Cochin & 1 & 2 & 7 & 6 & 16 \\
\hline Mangalore & 2 & 1 & 5 & 2 & 10 \\
\hline Diuhl & 2 & 3 & 3 & 4 & 12 \\
\hline Carachi & & & 1 & & 1 \\
\hline Chenai & & 1 & 3 & & 4 \\
\hline Machilipatam & & 2 & 4 & 2 & 8 \\
\hline Palicate & 3 & 5 & 4 & 2 & 14 \\
\hline Negapatnam & & 1 & 2 & 1 & 4 \\
\hline Bombay & & 1 & 2 & 1 & 4 \\
\hline Maliapur & & & 1 & 1 & 2 \\
\hline Chaul & 1 & 1 & 2 & 1 & 5 \\
\hline Surate & 2 & 2 & 4 & 2 & 10 \\
\hline Vishakhapatnam & & & 1 & 1 & 2 \\
\hline Honauar & 1 & 2 & 3 & 3 & 9 \\
\hline Beypore & & & 1 & 1 & 2 \\
\hline Bandra & & & 1 & 2 & 3 \\
\hline Basrur & 2 & 4 & 3 & 1 & 10 \\
\hline Quilón & & & & 1 & 1 \\
\hline Batticaloa & & & 1 & & 1 \\
\hline Trincomalee & & & 1 & 1 & 2 \\
\hline Colombo & & 1 & 3 & 1 & 5 \\
\hline Negombo & & & 2 & 1 & 3 \\
\hline Galle & & & 2 & 1 & 3 \\
\hline Pegu & 3 & 7 & 7 & 6 & 23 \\
\hline Malaca & 4 & 8 & 8 & 8 & 28 \\
\hline Queda & 1 & 2 & 3 & 4 & 10 \\
\hline Patamoi & & 2 & 4 & 1 & 7 \\
\hline Perai & & 1 & 4 & 1 & 6 \\
\hline Pekan & & 1 & 2 & & 3 \\
\hline Pattaya & & & 1 & & 1 \\
\hline Singapore & 1 & & & 1 & 2 \\
\hline Bangkok & & & 2 & & 2 \\
\hline Johor & & & & 1 & 1 \\
\hline Muar & & & & 1 & 1 \\
\hline
\end{tabular}

Dr. Antoni Picazo Muntaner. La evaluación de la percepción espacial y el peso cartográfico de los nódulos del Índico y Pacífico. 
Cuadro 2

\begin{tabular}{|c|c|c|c|c|c|}
\hline \multicolumn{6}{|c|}{ PUERTOS, MAR DEL SUR SIGLO XVI } \\
\hline PUERTO & $1500-1525$ & $1526-1550$ & $1551-1575$ & $1576-1600$ & Peso Absoluto \\
\hline Borneo & & 2 & 3 & 6 & 11 \\
\hline Daro & & & 1 & & 1 \\
\hline Manado & & & 3 & 1 & 4 \\
\hline Pamanukam & & & 1 & 1 & 2 \\
\hline Surabaya & & & 2 & 3 & 5 \\
\hline Dilli & & & 1 & & 1 \\
\hline Ternate & & & & 1 & 1 \\
\hline Tidoro & & & & 1 & 1 \\
\hline Palimban & & & & 1 & 1 \\
\hline Aceh & 1 & 2 & 3 & 2 & 8 \\
\hline Merak & & & & 1 & 1 \\
\hline Cantón & & 2 & 5 & 7 & 14 \\
\hline Quinzal & & & 3 & 2 & 5 \\
\hline Fushan & & & 1 & 4 & 5 \\
\hline Senzhen & & & 2 & 2 & 4 \\
\hline Fuzhou & & 1 & 3 & 3 & 7 \\
\hline Quanzhou & & & 1 & 4 & 5 \\
\hline Macao & & & 3 & 3 & 6 \\
\hline Ningbo & & & 1 & 1 & 2 \\
\hline Zhanton & & 1 & 1 & 2 & 4 \\
\hline Kochi & & & & 1 & 1 \\
\hline Senday & & & & 1 & 1 \\
\hline Kagoshina & & & 1 & 3 & 4 \\
\hline Nagasaki & & & 1 & & 1 \\
\hline Davao & & & 1 & & 1 \\
\hline Calanan & & & 1 & & 1 \\
\hline Tuburan & & & 1 & & 1 \\
\hline Manila & & & & 2 & 2 \\
\hline Natividad & & & & 1 & 1 \\
\hline Panamá & & & & 1 & 1 \\
\hline Callao & & & & 2 & 2 \\
\hline
\end{tabular}

1595 diferentes compañías holandeses comienzan a explotar los productos asiáticos a través del comercio directo. En apenas una década 96 barcos holandeses, con una capacidad de carga de 34.810 toneladas accedieron a varios puertos de la zona. Concretamente 9 viajes a Engano; 1 a Djaratan; 1 a Terrenate; 56 a Bantam, 13 a Aceh; 3 a Ceilán, 1 a Madagascar, 1 a Camboya y 11 a Johor. Por su parte de los ingleses de la EIC $^{45}$ comenzaron su penetración más tarde, en 1601 basándose más en grandes convoyes. En 1601 enviaron 5 naves a Bantam, desplazando 2.330 toneladas. En 1603 fueron 4 las que repitieron el mismo viaje con 2.200 toneladas y en 1604, una sola nave con capacidad de carga de 200 toneladas. 


\section{CONCLUSIONES.}

En cuanto al análisis de la evolución de la percepción espacial podemos matizar algunos puntos. En primer lugar el área estudiada dentro del Sistema Global, forma un subsistema, con dos sectores plenamente entrelazados. Por una parte el Índico, por otra el Pacífico.

En segundo lugar, y por la propia dinámica expansiva y comercial de Europa, las etapas cronológicas se dividen en dos períodos, la primera la perteneciente al siglo XVI, de penetración luso-hispánica; la segunda, la de los siglos XVII y XVIII, de inserción de otras potencias europeas y de masivo control económico de las mismas, en oposición completa al sistema mercantil tanto de portugueses como de españoles.

El análisis global de los pesos cartográficos ${ }^{46}$ de todos los puertos que aparecen en la cartografía de la época, y la comparación inter-áreas, desvela claramente aquella interconexión de los subsistemas. Para Robinson, “..Morphological studies of ports have been dominated by a concern with the port as a spatial entity, as a more-or less contiguous area devoted to modal interchange functions..." ${ }^{\prime 4}$. La diferencia entre ellas es muy clara, como se demuestra en la gráfica que se adjunta. En la primera etapa cronológica, que abarca de 1500 hasta 1525, en el mismo inicio de la presencia europea en la zona, el Índico se refleja en toda la cartografía con toda su extensión y, sobre todo, con una definición de nódulos muy extensa, mientras que el peso del Pacífico prácticamente es inexistente. La evolución fue paralela hasta la gran época de desarrollo, de 1551-75, en que el Índico se convirtió, sin ninguna duda, en el mercado más productivo para las economías europeas. En cambio, el rápido auge del Pacífico en los últimos 25 años de la centuria estudiada

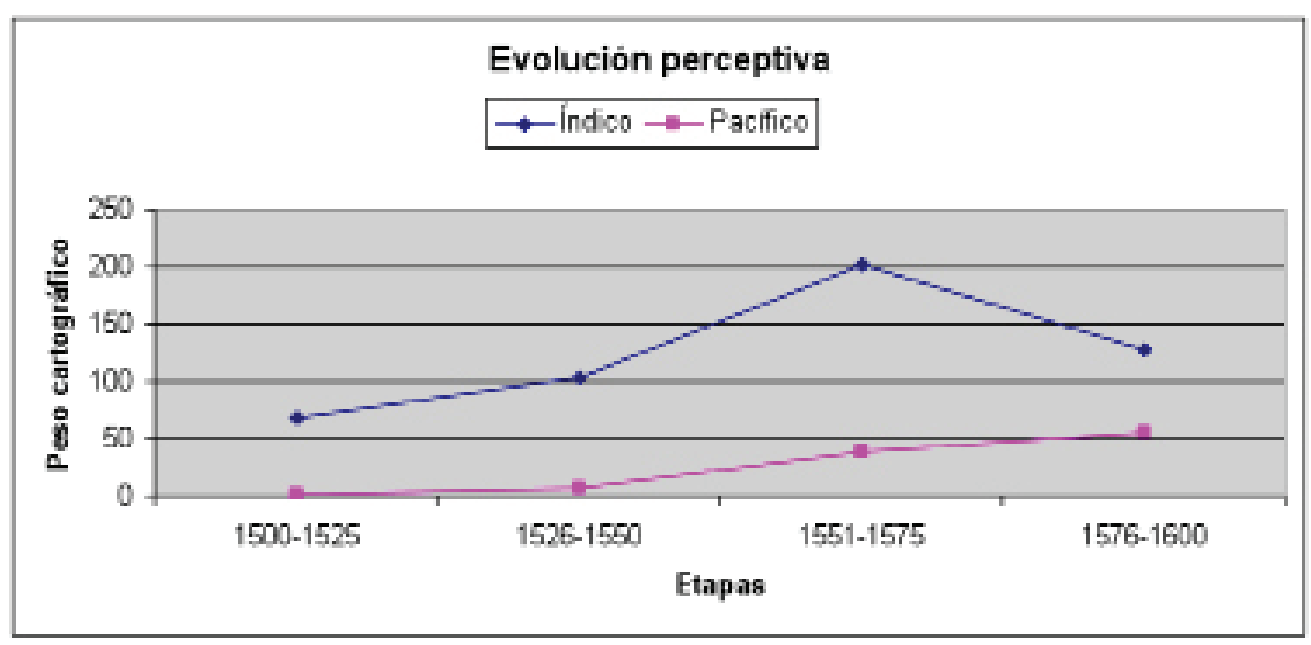

Figura 1. Gráfico Evolución perceptiva 
permite afirmar que aquellos puertos secundarios, de mínimo peso económico, tales como Quiloa, Mogadiscio o Zalala, desaparecieron de todos los mapas para entrar otros destinos del Pacífico que fueron cobrando auge mercantil ${ }^{48}$. Las dos áreas tuvieron su mayor diferencia representativa en el período de 1551-75, para reducir distancia -hasta un 50\%- en el último cuarto de siglo.

Por otra parte, pero en la misma dinámica de relación directa entre percepción espacial y actividad comercial, los índices de variación nos permiten evaluar las diferencias de un mismo puerto entre 1575-1600 respecto a 1500-1525. Así podemos ver como aquellos grandes puertos, centros nucleares de las actividades del tráfico en todas las épocas, como fueron Ormuz, Adén o Calicut, mantuvieron un mismo protagonismo, sin apenas cambios evolutivos. Se intentó, por todos los medios, que los mercaderes, nativos y extranjeros, se readaptasen a la nueva situación ${ }^{49}$. Por otro lado, las nuevas incorporaciones de grandes nódulos demuestran ese salto cualitativo en las representaciones, entre ellas Mombasa, Sohar, Damao, Goa y Queda que manifiestan la visión que el hombre europeo tuvo de esos nuevos espacios que iban integrándose dentro de sus esquemas mentales de percepción del mundo. Ese binomio de "percepción" de los grandes nódulos nucleares del Índico con el "comercio", es decir, la configuración de una "Imago mundi" basada en las posibilidades de negocio, en la obtención de riqueza, continuó madurando.

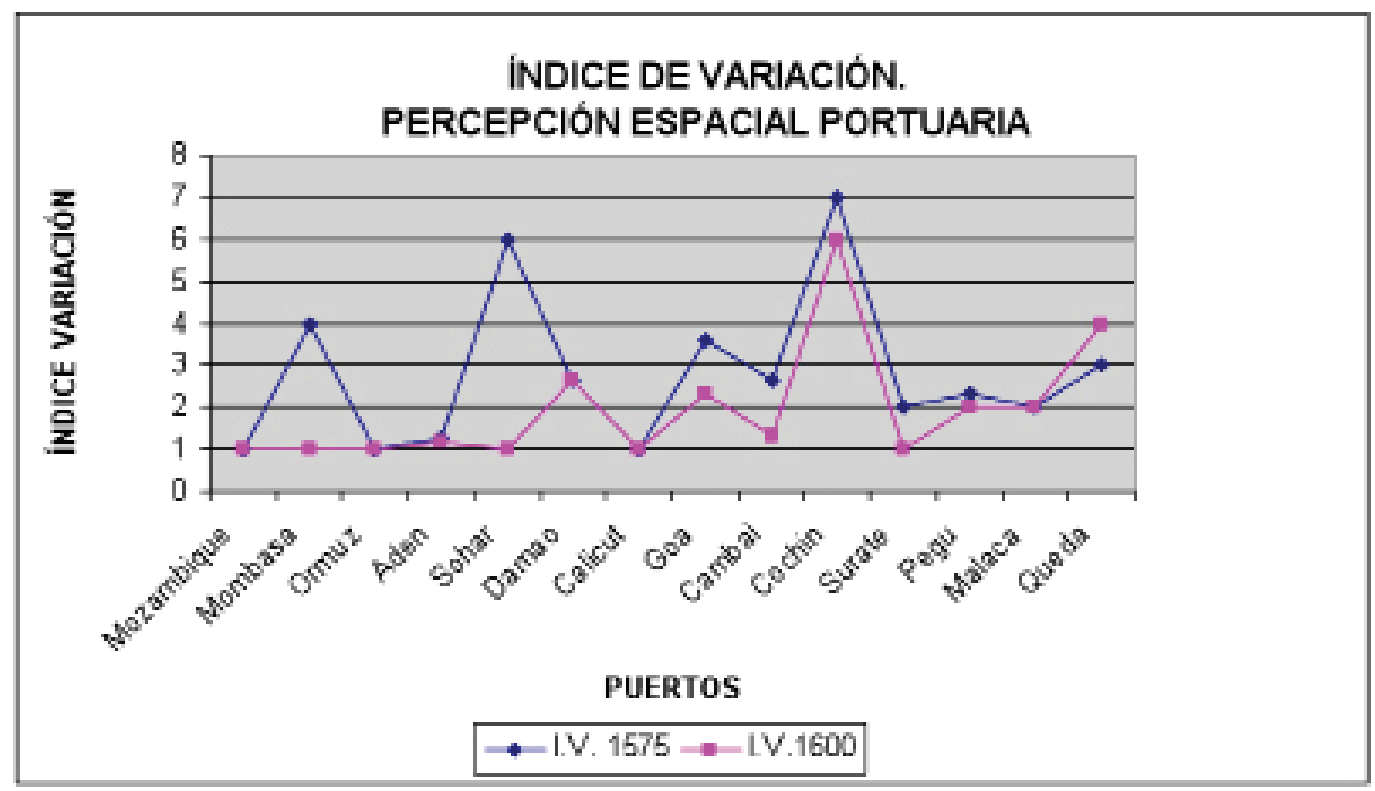

Figura 2. Gráfico Índice de variación.

El análisis del peso absoluto global de todo el Océano Índico también explica la situación de cambio en la visión europea, y de continuidad en la dinámica mercantil 
de todo el territorio. Cabría señalar la presencia de tres puntos de interconexión de grandes áreas. En primer lugar, en el sudeste asiático, Malaca y Pegu sobresalen como grandes centros. En segundo lugar, en el área de la India ${ }^{50}$, hallamos el mayor número de nódulos, y más importantes, especialmente Calicut, Goa, Cochin, Damao y Cambai. Finalmente, la zona de Oriente Medio, con Ormuz y Adén como nódulos centrales. La media del peso cartográfico, situada en 8’2 puntos, viene a reforzar lo que hemos apuntando anteriormente. La mayoría de puertos indios se encontraban muy por encima de ella, mientras que los de África, Oriente Medio, Ceilán y sudeste asiático estaban por debajo.

Por lo que se refiere al Pacífico cabe remarcar que, a medida que los puertos se iban integrando en el sistema comercial de las redes europeas, iban reflejándose en la cartografía. En muchas ocasiones su presencia significó la desaparición de otros nódulos de menor importancia en el imaginario colectivo del viejo mundo. Un análisis de los índices de variación de los puertos, de 1600 respecto a 1525, nos ilustra cómo cambió su percepción. La integración de los mismos en los mapas se fue gestando a medida que se penetraba en el mercado y cada vez se obtenía más información, mucho más detallada ${ }^{51}$. Borneo, Fuzhou y Cantón son los que presentan un índice de variación mayor. Esa variación se encuentra vinculada directamente, al menos en el Pacífico, al componente de la distancia. Buen ejemplo de ello es que los mapas de Japón ${ }^{52}$ comenzaron a representarse muy tardíamente, cuando las demás zonas y puertos estaban perfectamente integrados en el sistema cartográfico europeo.

El peso cartográfico absoluto del Pacífico da testimonio de un tipo de percepción que se halla ligada a dos vectores fundamentales. Por una parte al componente de penetración mercantil y traspaso de información; por otra, la relación de distancia. La conexión que existió entre mercados-distancia se articuló en un proceso mucho más amplio. El mercado no sólo está definido por las formas económicas, también por el espacio físico donde se ubica y por el factor tiempo. Así pues, el comercio transnacional del subsistema Indopacífico estaría supeditado a tres grandes condicionantes:

1- El tráfico disminuye con la distancia.

2- Los precios varían en cada puerto con grandes diferencias entre ellos.

3- Las barreras geográficas reflejan los impedimentos de la multitud de costes de transporte, tarifas y cuotas, así como los problemas de negociación ${ }^{53}$.

\section{BIBLIOGRAFÍA.}

- $\quad$ ABRANCHES, J.A. y BERNARD, H. « Les Instructions du Pere Valignano pour l'ambassade japonaise en Europe. (Goa, 12 decembre 1583) », Monumenta Nipponica, Vol. 6, No. 1/2 (1943), pp. 391-403. 
- $\quad$ ADAO DE FONSECA, Luis. Portugal entre dos mares, Madrid: Maphre, 1993.

- $\quad$ ARDAO, A. Espacio e Inteligencia, Barcelona: Equinoccio, 1983

- AUBIN, Jean. «Un Voyage de Goa à Ormuz en 1520 », Modern Asian Studies, Vol. 22, No. 3, (1988), pp. 417-432.

- BELTRÁN, R. (ED.). Maravillas, peregrinaciones y utopías. Literatura de viajes en el Románico,, Valencia: Universidad de Valencia, 2002.

- $\quad$ BINED, Alfred. La psicología del razonamiento,, Madrid: 1902.

- BOARD, C. y TAYLOR, R.M. « Perception and Maps: Human Factors in Map Design and Interpretation », Transactions of the Institute of British Geographers, New Series, Vol. 2, No. 1, Contemporary Cartography, (1977), pp. 19-36.

- BOLLNOW, Otto Friedrich. Hombre y espacio,, Barcelona: Labor, 1969.

- BRAUDEL, F. El Mediterráneo y el mundo mediterráneo en tiempos de Felipe II, México: FCE, 1980

- BROTTON, J..Trading Territories: mapping the early modern world, London: Reaktion Books, 1997.

- BUISSERET, D. La revolución cartográfica en Europa, 1400-1800: la representación de los nuevos mundos en la Europa del Renacimiento, Paidós: 2004.

- CANTINO, A. Carta d'Alberto Cantino ao Duque de Ferrara, Lisboa: Imprenta Nacional, 1909. SINGH JESSY, Joginder.History of Malaya (1400-1959), United Publishers: 1961.

- CASATI, R. Parts and Places. The Structures of Spatial Representation, Cambridge: MIT Press, 1999.

- CASSIER, Ernst. Filosofía de las formas simbólicas, México: FCE, 1976.

- $\quad$ CENCILLO, Luis. Tratado de las realidades, Madrid, 1971.

- CHITTICK, N.. África del este y oriente: los puertos y el comercio antes de la llegada de los portugueses, en VVAA ,Relaciones Históricas del Océano Índico,, Barcelona: Ed. Subal, 1983, pp. 15-26.

- DANCY, Jonathan. Introducción a la epistemología, Barcelona: Grijalbo, 1978.

- DISNEY, A. Twilight of the Pepper Empire: Portuguese Trade in Southwest India in the Early Seventeenth Century, Harvard: HUP, 1978.

- DOLLFUS, Olivier. El espacio geográfico, Barcelona: Oikos-Tau, 1976.

- DONKIN, R.A. Between East and West: The Moluccas and the Traffic in Spices Up to the Arrival of Europeans, Darby: Diane Publising, 2004.

- EDNEY, Matthew. « Theory and the History of Cartography », Imago Mundi, Vol. 48, (1996), pp. 185-191. 
- $\quad$ ERIKSON, E. Y BEARMAN, P. Routes into Newtwors. The structure of Englis Trade in The East Indies, 1601-1833, Columbia University Press, 2004.

- FIORANI, Francesca. The Marvel of Maps: Art, Cartography and Politics in Renaissance Italy, Yale: Yale University Press, 2005.

- FITCHE, J. G. Filosofía y Estética, Valencia: Universitat de València, 1998.

- FOX, Edward Whiting Fox. La Historia desde una perspectiva geográfica, Lleida: U. Lleida, 1998.

- FRANK, A.G. ReOrient. Global Economy in The Asian Age, Berkeley: U. California Press, 1998.

- $\quad$ GILLS, Barry, THOMPSON, W. Globalization and Global History, London: Routledge, 2006.

- GOULD, Peter. «The Structure of Space», Geografiska Annaler, Vol.79, No. 3, (1997), pp. 127-140.

- GUPTA, Ashin. «Indian Merchants and the Western Indian Ocean: The Early Seventeenth Century », Modern Asian Studies, Vol. 19, No. 3, (1985), pp. 481-499.

- HARLEY, J.B.; WOODWARD, David. The History of Cartography, Chicago: University of Chicago Press, 1987.

- HARRIS, C. «Power, Modernity, and Historical Geography », Annals of the Association of American Geographers, Vol. 81, No. 4, ( 1991), pp. 671-683.

- JAMES, W. «The Perception of Space. (I.) », Mind, Vol. 12, No. 45, (1887), pp. 1-30.

- JOLY, Fernand.La Cartografía,, Barcelona: Seix Barral, 1987.

- $\quad$ KEARNEY, Milo.The Indian Ocean in World History, London: Routledg, 2004.

- $\quad$ KLINGHOFFER, Arthur Jay; SICHERMAN, Harvey. The Power of Projections: How Maps Reflect Global Politics and History, N.Y.: Greenwood, 2006.

- $\quad$ KNAAP, G. y SUTHERLAND, H. Monson Traders, Leiden : KITLV Press, 2004.

- $\quad$ LUKÁCS, George.Estética, Barcelona: Grijalbo, 1982.

- $\quad$ MANSO PORTO, Carmen. Cartografía Histórica Portuguesa: catálogo de manuscritos, siglos XVII-XVIII, Madrid: Real Academia de la Historia, 1999.

- $\quad$ MAZLISH, B.; BUULTJENS, R. Conceptualizing Global History, Westview Press: 1993

- MCPHERSON, Kenneth. The Indian Ocean: A History of People and The Sea, N. Delhi: Oxford University Press, 1993.

- MERI, Josef. Medieval Islamic Civilization: an encyclopedia, Londres: Routledge, 2006.

- $\quad$ MERLEAU-PONTY, M..Fenomenología de la percepción,, México: FCE, 1957.

- MORRISON, T. y ROSSANO, M. «Learning from Maps: General Processes and Map-Structure Influences », Cognition and Instruction, Vol. 14, No. 1, (1996), pp. 109-137 . 
- NEWITT, Malyn. A History of Portuguese Overseas Expansion, 1400-1668, Londres: Routledge, 2005.

- OÑATIVIA, O. Dimensiones de la percepción, Tucumán: Universidad de Tucumán, 1963.

- $\quad$ PEARSON, M. Spices in the Indian Ocean World, Variorum: 1996.

- POLITZ, Alfred. «On the Origin of Space Perception », Philosophy and Phenomenological Research, Vol. 40, No. 2, (1979), pp. 258-264.

- $\quad$ PRAKASH, Om. International Consortiums, Merchants Networks and Portuguese trade with Asia in the Early Modern Period, en XIV International Economic History Commerce, Helsinki: 2006.

- ROBINSON, Ross. "Modelling the Port as an Operational System: A Perspective for Research », Economic Geography, Vol. 52, No. 1 (1976), pp. 71-86.

- $\quad$ ROSS, Robert, Clothing. A Global History: Or, the Imperialists’ New Clothes, Polity: 2008.

- $\quad$ RUIZ MARTÍN, F. Pequeño capitalismo, gran capitalismo: Simón Ruiz y sus negocios en Florencia, Barcelona: Crítica, 1990 .

- SÉE, Henri. Orígenes del capitalismo moderno, México: FCE, 1977.

- SKINNER, G.W. (Ed.).The city in Late Imperial China, Stranford: Stranford U. Press, 1998.

- SWENSON, Leland. Teorías del aprendizaje, Barcelona: Paidos: 1991.

- THARLING, N. The Cambridge History of Southeast Asia, Vol I, Part. II. From 1500 to 1800, Cambridge: Cambridge U. Press, 1999.

- $\quad$ TRACY, James. The Rise of Merchant Empires: Long-distance Trade in the Early Modern World, 1350-1750, Cambridge: Cambridge University Press, 2004.

- $\quad$ TROWER, Norman. Maps and Civilization: Cartography in Culture and Society, Chicago: University Press, 1999.

- VARELA MARCOS, J. El Tratado de Tordesillas en la política Atlántica castellana, Valladolid: Universidad de Valladolid, 1997.

- VILA VALENTÍ, J. Introducción al estudio teórico de la Geografía, Barcelona: Ariel, 1983.

- VINING, R. «Delimitation of Economic Areas: Statistical Conceptions in the Study of the Spatial Structure of an Economic System », Journal of the American Statistical Association, Vol. 48, No. 261, (1953), pp. 44- 64.

- VOLCKART, Oliver.The Influence of Information Cost on The Integration of Financial Markets: Northerm Europe, 1350-1560,, Institute of Economic History, Humbolt University: Berlin, 2006.

- $\quad$ VVAA. Cartographie historique du golfe persique, Wilsele: Peeters Publishers, 2006.

- VVAA. Descubrimientos y cartografía en la época de Felipe II, Instituto Interuniversitario de Estudios de Iberoamérica y Portugal, 1999. 
- WALLERSTEIN, I. El capitalismo histórico, México: Siglo XXI, 1988.

- WALLERSTEIN, I. El moderno sistema mundial II: el mercantilismo y la consolidación de la economía-mundo europea, 1600-1750, Madrid: Siglo XXI, 1984.

- WOOD, L.J. "Perception Studies in Geography », Transactions of the Institute of British Geographers, No. 50, (1970), pp. 129-142.

\section{CITAS Y NOTAS}

* Este artículo está financiado y forma parte del proyecto de investigación de EUROCORES, European Science Foundation "Dynamic Complexity of Cooperation-Based SelfOrganizing Networks in the First Global Age (DynCoopNet) “. (06-TECT-FP-004) así como del Ministerio de Educación y Ciencia SEJ2007-29226-E/SOCI. Debo agradecer a los evaluadores del presente artículo las sugerencias realizadas que han sido incorporadas al mismo.

1 Para las cuestiones más teóricas y la conceptualización, vid. MAZLISH, B.; BUULTJENS, R. Conceptualizing Global History, Westview Press: 1993 y también la obra de GILLS, Barry, THOMPSON, W. Globalization and Global History London: Routledge, 2006. El impacto europeo en la economía ha sido excelentemente tratado por ROSS, Robert, Clothing: A Global History: Or, the Imperialists' New Clothes, Polity: 2008.

2 BRAUDEL, F. El Mediterráneo y el mundo mediterráneo en tiempos de Felipe II, México: FCE, 1980 y también del mismo autor, Civilización material, economía y capitalismo, siglos XV-XVIII, Madrid: Alianza, 1984.

3 HARLEY, J.B.; WOODWARD, David. The History of Cartography, Chicago: University of Chicago Press, 1987.

4 POLITZ, Alfred. « On the Origin of Space Perception », Philosophy and Phenomenological Research, Vol. 40, No. 2, (1979), pp. 258-264.

5 JAMES, W. « The Perception of Space. (I.) », Mind, Vol. 12, No. 45, (1887), pp. 1-30, p. 13.

6 FOX, Edward Whiting Fox. La Historia desde una perspectiva geográfica, Lleida: U. Lleida, 1998, p. 57.

7 HARRIS, C. " Power, Modernity, and Historical Geography », Annals of the Association of American Geographers, Vol. 81, No. 4, ( 1991), pp. 671-683. Nos explica la visión que algunos autores, tales como Foucault, Habermas, Giddens o Mann, tuvieron de la relación entre "poder y modernidad".

8 WALLERSTEIN, I. El moderno sistema mundial II: el mercantilismo y la consolidación de la economía-mundo europea, 1600-1750, Madrid: Siglo XXI, 1984.

9 EDNEY, Matthew. «Theory and the History of Cartography », Imago Mundi, Vol. 48, (1996), pp. 185-191, p. 189. 
WOOD, L.J. « Perception Studies in Geography », Transactions of the Institute of British Geographers, No. 50, (1970), pp. 129-142.

11 Vid. el magnífico estudio de MORRISON, T. y ROSSANO, M. « Learning from Maps: General Processes and Map-Structure Influences », Cognition and Instruction, Vol. 14, No. 1, (1996), pp. 109-137, p. 110.

12 SÉE, Henri. Orígenes del capitalismo moderno, México: FCE, 1977. RUIZ MARTÍN, F. Pequeño capitalismo, gran capitalismo: Simón Ruiz y sus negocios en Florencia, Barcelona: Crítica, 1990 y también WALLERSTEIN, I. El capitalismo histórico, México: Siglo XXI, 1988.

13 DOLLFUS, Olivier. El espacio geográfico, Barcelona: Oikos-Tau, 1976.

14 Para una mayor información sobre el proceso formativo de lectura de mapas y la relación entre autor-lector vid. BOARD, C. y TAYLOR, R.M. «Perception and Maps: Human Factors in Map Design and Interpretation », Transactions of the Institute of British Geographers, New Series, Vol. 2, No. 1, Contemporary Cartography, (1977), pp. 19-36.

15 Sobre una reflexión de los puertos del Índico, vid. CHITTICK, N. « África del este y oriente: los puertos y el comercio antes de la llegada de los portugueses », VVAA. Relaciones Históricas del Océano Índico, Barcelona: Ed. Subal, 1983, pp. 15-26.

16 Para zonas extraeuropeas sugerimos la magnífica obra de SKINNER, G.W. (Ed.). The city in Late Imperial China, Stranford: Stranford U. Press, 1998.

17 Un claro ejemplo de esta subjetividad lo hallamos en el mapa de China traducido y reelaborado por el jesuita Francesco Brancati, en 1661. Vid. GOLVERS, Noël, « China : Francesco Brancati, S.J. and the Map (1661 ?) of Sungchiang », Imago Mundi, 52 (2000), pp. 30-42. Brancati transformó notablemente el contenido y la información del mapa. De una representación geográfica en lo que primaba eran los ríos, canales y ciudades, se pasó a una información misional, básicamente cristiana, reflejando los intereses catequizadores de los europeos.

18 Entre algunos de los mapas que hemos utilizado se hallan: Anónimo, "Mapamundi Borgiano", 1400; Walsperger, "Mapamundi", 1448; Anónimo, "Rudimentum Navitiarum", 1474; Ptolomeo, "Mapamundi", 1482; Cantino, "Planisferio", 1502; Pedro Reinel, "Carta", 1518; Fries, "Typus Universalis", 1522; Gaspar Correia, "Roteiro", 1550; Paolo Forlani, "Universalis Descriptione", 1565; Johannes Pontanus, "Tabula Geograph inqua Europaeae, Africaeae, Asiaeae", 1611; Hugo Allard, "Nova Tabula India Orientalis", 1650; Phillip Cluver, "Atlas", 1659; Jean Baptiste Nolin, "Asie selon les memories les plus nouveaux", 1690 ; Guillaume de l'Isle, "Orbis Vetembus noti tabula nova “, 1715 ; Edward Henry Roberts, "Carta Generale “, 1732 ; Le Rouge, "Mappemonde “, 1748....

19 Entre las múltiples obras que analizan la expansión portuguesa cabríamos destacar, ADAO DE FONSECA, Luis. Portugal entre dos mares, Madrid: Maphre, 1993. NEWITT, Malyn. A History of Portuguese Overseas Expansion, 1400-1668, Londres: Routledge, 2005.

20 Véase por ejemplo la magna obra de MERI, Josef. Medieval Islamic Civilization: an enciclopedia, Londres: Routledge, 2006. Por otra parte, la magnífica obra de PEARSON, M. Spices in the Indian Ocean World, Variorum: 1996 analiza detenidamente el tráfico contractual de especias en el Egipto de los mamelucos y sus implicaciones económicas en Oriente Medio. 
22 Entre todas las obras de cartografía destaca la magna "Monumenta Cartographica Portugalia”, editada en Lisboa en 1960. Entre las más recientes cabría citar MANSO PORTO, Carmen. Cartografía Histórica Portuguesa: catálogo de manuscritos, siglos XVII-XVIII, Madrid: Real Academia de la Historia, 1999, en donde se pueden observar la gran fortificación de la metrópoli en el siglo XVII y comparar con la evolución defensiva de las "feitorias" del Índico. También sugerimos la de TROWER, Norman. Maps and Civilization: Cartography in Culture and Society, Chicago: University Press, 1999 en donde explica como la cartografía es un excelente barómetro para medir la actividad cultural de una sociedad y, como no, para determinar como evoluciona la imagen del mundo.

23 KEARNEY, Milo.The Indian Ocean in World History, London: Routledg, 2004. En TRACY, James. The Rise of Merchant Empires: Long-distance Trade in the Early Modern World, 1350-1750, Cambridge: Cambridge University Press, 1990 aún hallaremos aquella idea de la gran importancia del comercio mediterráneo, especialmente veneciano, del comercio de productos asiáticos. En cambio, DONKIN, R.A. Between East and West: The Moluccas and the Traffic in Spices Up to the Arrival of Europeans, Darby: Diane Publising, 2003 presenta una interpretación mucho más interdisciplinar y espacial.

24 VOLCKART, Oliver. The Influence of Information Cost on The Integration of Financial Markets: Northerm Europe, 1350-1560, Institute of Economic History, Humbolt University: Berlin, 2006.

KNAAP, G. y SUTHERLAND, H. Monson Traders, Leiden : KITLV Press, 2004.

Véase NEWITT, op. cit. y la ya clásica de CANTINO, A. Carta d'Alberto Cantino ao Duque de Ferrara , Lisboa: Imprenta Nacional, 1909. Pudiera ser que, como otra cartografía de la época, el mapa hubiera sufrido retoques en los años posteriores a 1506.

Para la historia de la zona véase SINGH JESSY, Joginder. History of Malaya (1400-1959), United Publishers: 1961 pero sobre todo la de THARLING, N. The Cambridge History of Southeast Asia, Vol I, Part. II. From 1500 to 1800, Cambridge: Cambridge U. Press, 1999 y en ella, de forma especial, el capítulo de ANDAYA, Barbara Watson. Political Development between the Sixtheenth and Eighteenth Centuries, pp. 58-116.

28 KLINGHOFFER, Arthur Jay;SICHERMAN, Harvey. The Power of Projections: How Maps Reflect Global Politics and History, N.Y.: Greenwood, 2006.

Vid. VVAA. Descubrimientos y cartografía en la época de Felipe II, Instituto Interuniversitario de Estudios de Iberoamérica y Portugal, 1999 y FIORANI, Francesca. The Marvel of Maps: Art, Cartography and Politics in Renaissance Italy, Yale: Yale University Press, 2005.

30 Vid. VVAA.Cartographie historique du golfe persique, Wilsele: Peeters Publishers, 2006.

31 Vid. MERLEAU-PONTY, M. Fenomenología de la percepción, México: FCE, 1957; ARDAO, A. Espacio e Inteligencia, Barcelona: Equinoccio, 1983, especialmente recomendable para el tema en cuestión el capítulo "Crisis en la idea de Historia como Geo-historia". También, la excelente obra de CASATI, R. Parts and Places. The Structures of Spatial Representation, Cambridge: MIT Press, 1999. 
BLASCO, Josep Lluís. Teoría del Conocimiento, Valencia: Universitat de Valencia, 2004, afirma que la percepción es la primera fase del conocimiento.

33 OÑATIVIA, O. Dimensiones de la percepción, Tucumán: Universidad de Tucumán, 1963.

34 Vid. BOLLNOW, Otto Friedrich. Hombre y espacio, Barcelona: Labor, 1969.

35 VILA VALENTÍ, J. Introducción al estudio teórico de la Geografía, Barcelona: Ariel, 1983, p. 71.

JOLY, Fernand. La Cartografía, Barcelona: Seix Barral, 1987, p. 40.

BINED, Alfred. La psicología del razonamiento, Madrid: 1902, p. 10.

LUKÁCS, George. Estética, Barcelona: Grijalbo, 1982, p. 424

SWENSON, Leland. Teorías del aprendizaje, Barcelona: Paidos: 1991, p. 37.

FITCHE, J. G. Filosofía y Estética, Valencia: Universitat de València, 1998, p. 155.

DANCY, Jonathan. Introducción a la epistemología, Barcelona: Grijalbo, 1978.

CASSIER, Ernst en. Filosofía de las formas simbólicas, México: FCE, 1976, pp. 173.

CENCILLO, Luis Tratado de las realidades, Madrid, 1971, p. 52.

MCPHERSON, Kenneth. The Indian Ocean: A History of People and The Sea, N. Delhi: Oxford University Press, 1993, p. 3

ERIKSON, E. Y BEARMAN, P. Routes into Newtwors. The structure of Englis Trade in The East Indies, 1601-1833, Columbia University Press, 2004.

Para GOULD, Peter. « The Structure of Space », Geografiska Annaler, Vol. 79, No. 3, (1997), pp. 127-140, la estructura espacial es el elemento fundamental de la geografía.

ROBINSON, Ross. "Modelling the Port as an Operational System: A Perspective for Research », Economic Geography, Vol. 52, No. 1 (1976), pp. 71-86, p. 75.

VINING, R. « Delimitation of Economic Areas: Statistical Conceptions in the Study of the Spatial Structure of an Economic System », Journal of the American Statistical Association, Vol. 48, No. 261, (1953), pp. 44- 64 , pág 51, cita “...the spatial structure of a human economy should be regarded conceptually as virtually a continuum...".

49 GUPTA, Ashin. «Indian Merchants and the Western Indian Ocean: The Early Seventeenth Century », Modern Asian Studies, Vol. 19, No. 3, (1985), pp. 481-499, p. 490, lo explica del siguiente modo: "...The more we go into close, local analysis of particular situations the more we realize that general concepts look very different at close quarters. 'The European factor' varies enormously according to time, place and the context. 'The Indian merchant' falls apart in factions. It becomes difficult to say what 'the state' is when one considers the actual men representing it in a concrete situation. But of course they are all there and I shall be particularly concerned with the relationship between the Indian merchants and the political powers, both Indian and European, and try to show how in a changing context of power these merchants sought their salvation...". 
50 DISNEY, A. Twilight of the Pepper Empire: Portuguese Trade in Southwest India in the Early Seventeenth Century, Harvard: HUP, 1978.

51 Además de los roteiros, algunos viajes proporcionaron un gran volumen de información, vid. AUBIN, Jean. «Un Voyage de Goa à Ormuz en 1520 », Modern Asian Studies, Vol. 22, No. 3, (1988), pp. 417-432. Describe el viaje de la nave Santa Maria do Monte, redactado por Cristovao Afonso de Goa a Ormuz y comandada por el capitán y factor comercial Paris Corbinell.

52 Un ejemplo de traspaso de información lo hallamos en las relaciones que recababan marinos, capitanes o embajadores. Sobre Japón, véase ABRANCHES, J.A. y BERNARD, H. « Les Instructions du Pere Valignano pour l'ambassade japonaise en Europe. (Goa, 12 decembre 1583) », Monumenta Nipponica, Vol. 6, No. 1/2 (1943), pp. 391-403, y como cita en la p. 395 que "...levara consigo rol de todas as cousas y papeis que leva, levado apartadamente os papeys q se han de deyxar en Portugal y os q ha de levar a Roma, y na viagen yra lendo muytas vezes os que tras dos tratados da India y de Japao, y da cosulta q se fez en Japao y aquy os años pasados y a cogragaçao q fizemos agora, communicandoos tamben co o padre Mesquita pera q ambos estem bem informados do q han de dizer y fazer, y tenhao tudo prestos na memoria pera poder dar boa informaçao das cousas...".

53 EATON, J. y KORTUM, S. « Technology, Geography, and Trade », Econometrica, Vol. 70, No. 5, (2002), pp. 1741-1779. 